\title{
Histórias que transformam: o Pibid em História e a formação docente
}

\section{Stories that Transform: The PIBID and the Teaching Training}

\author{
Claudia Cristina da Silva Fontineles* \\ Thiago Rodrigues Frota ${ }^{*}$
}

\section{Resumo}

O presente trabalho visa discutir as transformações e permanências ocorridas na formação dos professores de História entre o período da ditadura militar no Brasil e o processo de redemocratização do país, entre a década de 1960 e os anos 2000, em especial no que se refere à formação de professores, buscando entender em que medida o Programa Institucional de Bolsas de Iniciação à Docência (Pibid) contribuiu para melhorar a formação docente, sobretudo no curso de História. Para tanto, recorremos à revisão bibliográfica sobre o tema, à análise de conteúdo dos documentos oficiais do referido Programa, além de adotarmos a metodologia da História Oral Temática em entrevistas realizadas com os participantes do Programa (graduandos, professores universitários e professores da rede pública de Ensino Básico), objetivando analisar como o Pibid contribuiu efetivamente para a formação acadêmico-profissional dos sujeitos envolvidos.

Palavras-chave: história; ensino de história; formação docente.

\begin{abstract}
The present work aims to discuss the transformations and permanences that occurred in the training of the History teacher between the period of the military dictatorship in Brazil and the redemocratization process of the country, between the 1960s and the 2000s, especially in relation to the training of teachers in that interstice, seeking to understand what extent the "Programa Institucional de Bolsas de Iniciação à Docência" (PIBID) contributed to improve the teacher training, mostly in the Degree in History Course. For that, it appealed to the bibliographic review about the theme, to the content analysis of the officiate documents from that Program, besides the methodology of the Thematic Oral History apart interviews with the Program participants (undergraduates, professor and teachers of the public school system of Elementary School), aiming to analyse how the PIBID contributed effectively to the academic-professional training of the subjects involved in the Project.

Keywords: history; teaching history; teacher training.
\end{abstract}

\footnotetext{
* Universidade Federal do Piauí (UFPI), Teresina, PI, Brasil. cfontinelles@yahoo.com.br

${ }^{*}$ Mestre em História, UFPI. Professor, rede privada de ensino, Teresina, PI, Brasil. thiagorodriguesfrota@hotmail.com
} 
As grandes mudanças políticas e econômicas ocorridas no final do século XX causaram muita perplexidade entre professores e estudantes de História em geral, criando, em certos círculos, atitudes de ceticismo com relação ao próprio conhecimento histórico, $o$ valor do ensino de História nas escolas e o seu papel transformador.

(Pinsky; Pinsky, 2008, p. 17)

Tendo em vista que a educação, a partir da década de 1980, tem vivenciado um período de mudanças consideráveis na organização do sistema de ensino, dos currículos escolares e das diretrizes curriculares dos cursos de formação de professores, no Brasil - transformações influenciadas diretamente pelo processo de (re)democratização vivenciado pelo país - cabe investigar como foi pensada a formação de professores de História e como essa formação interferiu no ensino de história na Educação Básica.

Além disso, é preciso compreender como as políticas públicas adotadas, após a queda do regime ditatorial (1964-1985), em especial após a implantação do Programa Institucional de Bolsas de Iniciação à Docência (Pibid), nos anos 2000, vieram a interferir nesse contexto, representando transformações na formação docente e no ensino de história no país.

Assim, o presente trabalho visa discutir as transformações e permanências ocorridas na formação dos professores de história entre o período da ditadura militar no Brasil e o processo de redemocratização do país (entre as décadas de 1960 e 2000), em especial no que se refere à formação de professores, buscando entender em que medida o Pibid contribuiu para melhorar a formação docente e para o ensino de história, sobretudo no curso de Licenciatura em História.

Para tanto, recorremos aos estudos bibliográficos sobre o tema, à consulta e análise dos documentos oficiais do referido Programa, além de adotarmos a metodologia da História Oral Temática em entrevistas realizadas com os participantes do Programa (graduandos, professores universitários e professores da rede pública de Ensino Básico), visando analisar como o Pibid influenciou na formação acadêmico-profissional dos sujeitos envolvidos no projeto, em especial no que se refere à formação docente dos graduandos de História da 
Universidade Federal do Piauí (UFPI). A escolha do lócus da pesquisa justifica-se pelo fato de ter sido essa a pioneira na implantação do Programa no estado do Piauí.

As fontes consultadas neste trabalho nos deram indícios de que "ler, criticar, discutir, reunir-se com outras pessoas interessadas em não morrer profissional e pessoalmente podem ser caminhos para atenuar esse desgaste" da profissão docente e o desprestígio do ensino de história no Brasil (Pinsky; Pinsky, 2008, p. 11). A partir da inter-relação entre os sujeitos envolvidos é que se estabelece uma experiência de troca de saberes, ao compartilhar a ideia de que exercer o ofício do professor historiador significa, antes de tudo, entender que o conhecimento é uma construção das experiências, vivências, discussões e leituras que esse profissional faz de si mesmo e do mundo que o cerca.

Dessa maneira, ao pesquisar e ensinar História, o profissional deve buscar na sua prática a validade do que faz para si e para os estudantes, com quem ao mesmo tempo ele ensina e aprende, conforme afirma Paulo Freire: "Não há docência sem discência, as duas se explicam e seus sujeitos, apesar das diferenças que os conotam, não se reduzem à condição de objeto um do outro. Quem ensina aprende ao ensinar e quem aprende ensina ao aprender. Quem ensina, ensina alguma coisa a alguém [...]" (Freire, 2000, p. 25).

$\mathrm{Na}$ presente pesquisa adotamos a metodologia da História Oral, valiosa para conhecer as reminiscências dessa relação, pois é uma história do presente que se dá por uma relação entre entrevistador e entrevistado, articulada a ideias orientadas, gravações, e norteada por uma problemática central. A manifestação mais conhecida de fontes orais é a entrevista. Esse será um dos nossos mecanismos de construção do conhecimento aqui apresentado. Procuraremos discutir como as entrevistas individuais se comunicam com o coletivo, o que caracteriza a História Oral temática (Alberti, 2005, p. 37-39; 2004), que é a proposta utilizada junto aos entrevistados da presente pesquisa, na medida em que visa pesquisar o envolvimento dos sujeitos entrevistados com a temática em estudo.

Algumas das entrevistas foram realizadas por via eletrônica, recorrendo a mídias que permitiram o acesso a pessoas que estavam impedidas de se deslocar, possibilitando outra forma narrativa de se lidar com as declarações.

Partimos da premissa de que a atual realidade educacional brasileira está diretamente ligada à tradição autoritária e desigual no acesso ao ensino no 
Brasil, durante os governos militares, sobretudo no que concerne ao lugar do ensino na estrutura curricular dos cursos de formação docente, e que o Pibid contribuiu para inscrever uma forma diferente de pensar e de atuar em relação a essa formação e à atuação docente no cenário educacional, em especial no curso de História.

\section{O ENSINO DE HistóRIA: UMA FORMAÇÃO HUMANISTA?}

Esse passado que se constitui como herança onerosa dos governos dos generais na história da educação nacional caracterizou-se por um ensino autoritário, especialmente na área das ciências humanas (geografia e história), em decorrência da obliteração da formação humanista e crítica pelos governos naquele contexto histórico. Isso, em boa medida, está inter-relacionado ao

Longo processo de desqualificação pelo qual vem passando o magistério - principalmente os professores das denominadas ciências humanas - que ao longo das últimas décadas, em nome da valorização das habilidades técnicas e de uma pretensa visão de ciência, abomina qualquer reflexão acerca do significado das práticas sociais e que, em nome do progresso da humanidade, vai fazendo suas vítimas. (Reis, 1999, p. 12)

É importante dizer que essa desvalorização do magistério não se restringe ao período da ditatura militar, uma vez que advém de práticas e discursos partilhados em experiências anteriores, além de terem reverberado em tempos posteriores e de persistirem no meio acadêmico, de maneira geral, e no Ensino Básico, de maneira específica, blindados por uma ainda persistente cultura universitária que dificulta a aproximação entre o ensino e a pesquisa. Reforça-se, ainda, a dicotomia existente entre a Academia e a Educação Básica, pois a Universidade prioriza o campo da pesquisa em detrimento da formação de professores, como se uma área estivesse dissociada da outra, quando estão imbricadas e inter-relacionadas (Guimarães, 2004, p. 12).

Essas ideias conservadoras negam a cultura escolar, ou seja, a existência de saberes específicos, não só das instituições de Ensino Básico (as escolas), mas da docência em toda a sua extensão. Esse pensamento é mais intenso em relação às escolas básicas, pois ainda persiste a desconfiança sobre a capacidade 
de elaboração e produção do saber escolar pelos integrantes da comunidade que as compõe.

Essa forma de se conceber o conhecimento, assim como sua produção e sua forma de transmissão, que predominou no período dos governos militares, vem sendo repensada na contemporaneidade. Mesmo com o esforço nesse sentido, o conhecimento histórico ainda está imerso e assombrado pelo paradigma da ciência moderna, na qual a realidade é vista como existindo em si mesma, dissociada do sujeito do conhecimento.

Dessa forma, continua existindo no seio da sociedade acadêmica uma visão fragmentada, que vê nas universidades e nos professores pesquisadores o núcleo detentor e produtor de conhecimento, e nas escolas e professores da educação básica os receptores e reprodutores do saber produzido nas Instituições de Ensino Superior (IES).

Evidencia-se na sala de aula dessa vertente o apego exclusivista a metodologias de ensino e a modelos de avaliação que procuram reproduzir conhecimentos por meio da memorização e de repetições exaustivas. Há, assim, uma relação verticalizada entre estudante e professor, em que o primeiro aparece como reprodutor do conhecimento que lhe é repassado em sala de aula, sem as devidas problematizações.

Essa concepção foi responsável pela polarização entre a pesquisa e a docência nas graduações - mesmo entre as Licenciaturas -, como se ambas não pudessem se relacionar, e, o pior, tendendo a valorizar a primeira em detrimento da segunda. Isso fragilizou a dimensão da docência, o que afetou o envolvimento da Universidade com a formação de professores ou com quaisquer dimensões voltadas para esse tema:

Estudos e pesquisas, bem como a formação de professores, têm sido realizados, preferencialmente, no campo da educação que oferece instrumental teórico próprio e essencial, mas insuficiente quando tratamos do ensino em perspectiva interdisciplinar, e tendo como pressuposto a mobilização de saberes pelos professores, e não apenas técnicas de transmissão. Produzidos neste campo, ressentem-se, também, de desprestígio e da desautorização daqueles que exercem o ofício de historiador, que desconfiam de conhecimentos produzidos "fora da oficina". Por outro lado, trabalhos sobre o ensino, realizados no âmbito da história, ressentem-se da falta de subsídios de autores que analisam aspectos próprios aos 
processos educativos, com instrumental que considera as especificidades da razão pedagógica. (Monteiro, 2016, p. 8)

Entendemos que é necessário buscar formas de aproximar a teoria à prática, bem como desmistificar a ideia de que esses conhecimentos não fazem parte do trabalho de um historiador ou não trazem um saber específico, uma vez que um profissional que almeja ser um bom pesquisador em história deveria valorizar a docência e seu poder institucional e social.

Nessa perspectiva, a revisão do ensino de história se configura como uma necessidade em face dos reclames educacionais na atualidade, os quais demandam uma forma de ensino que supere a simples transmissão de conhecimentos. Afinal, somente o acesso a esse saber já não é suficiente, ainda mais quando ele se encontra dissociado da realidade social em que as pessoas estão inseridas.

Segundo Ana Maria Monteiro, a escola "mais do que um local de instrução e transmissão de saberes, passou a ser considerada como espaço configurado e configurador de uma cultura escolar onde se confrontam diferentes forças e interesses sociais, econômicos, políticos e culturais” (Monteiro, 2016).

Complexidades, incertezas, instabilidades, particularidades e conflitos revelam que os sujeitos "não podem se encaixar em esquemas preestabelecidos do tipo taxonômico e processual” (Monteiro, 2016, p. 10), tal como um receituário médico. Uma característica fundamental para esse rompimento é o desenvolvimento de uma consciência histórica (Rüsen, 2001). ${ }^{1}$

O desenvolvimento dessa consciência histórica permite visualizar que “professores e alunos são sujeitos, portadores de visões de mundo e interesses diferenciados, que estabelecem relações entre si com múltiplas possibilidades de apropriação e interpretação" do mundo (Monteiro, 2016, p. 10). Esse entendimento aponta para um caráter dinâmico e necessário dessa categoria especial de pensamento, no sentido de construção de um indivíduo dotado de conhecimentos que auxiliem na sua compreensão das variadas formas de o ser humano existir enquanto ser social.

Além disso, favorece o reconhecimento das diferenças que encontramos ao longo de nossa existência como traço humano por excelência, estimulando a compreensão do tempo e do espaço como objeto fundamental para entender determinada realidade histórica. É essencial investir na formação do profissional docente, para que ele seja capaz de articular os saberes produzidos na 
academia com a sua prática em sala de aula, analisando a construção do saber escolar pelo encontro entre a historiografia e o saber ensinado nas escolas, o currículo em ação. Revela-se, assim, que, para existir um bom professor, deve existir antes um pesquisador, que vislumbre em suas fontes de estudos excelentes instrumentos de ensino. Acreditamos que

Talvez o primeiro passo seja reconhecer que não estamos apartados dessa sociedade e que nós, profissionais da história, integramos essa sociedade e nela convivemos e interagimos. Inicialmente, é necessário admitir que é nela que somos objetivados, mas também onde construímos nossas subjetivações, e mais, reconhecer que é a partir dela que projetamos nossos ideais e nossas ações no campo pessoal e no campo de nossa formação profissional como docentes e pesquisadores. Formação essa entendida como algo contínuo e permanente, que se desenvolve em diferentes espaços, e que deriva da "relação entre sujeitos, saberes e práticas”. (Fontineles; Sousa Neto, 2017, p. 201)

É importante, então, reconhecer que uma prática educacional significativa parte da percepção de que os cursos de licenciatura formam, antes de tudo, professores/educadores. À medida que esses educadores/pesquisadores compartilham ideias, trocam experiências e leituras, o conhecimento histórico se enriquece, e o olhar sobre sua prática se amplia a ponto de enxergar a escola como um espaço intelectualmente autônomo, superando a dicotomia existente entre teoria e prática e estabelecendo uma cultura escolar. Nesse contexto, percebe-se uma maior visibilidade para a formação de professores, principalmente no que tange à formação inicial.

\section{A ditadura militar no Brasil E O Desprestígio DA EduCAÇÃo E do ENSINO DE História}

A década de 1960 caracteriza-se por um momento de profundas transformações no cenário brasileiro. No que se refere à História, a disciplina enfrentou um período conturbado no que diz respeito à formação de professores, ao papel da disciplina no currículo escolar e ao conteúdo a ser ensinado nas escolas, pois os governos militares implantaram um projeto de governo marcado pelo desprestígio do ensino de história, e seus reflexos e resquícios ainda são sentidos no 
século XXI, mesmo em um contexto democrático: "Nas mudanças educacionais implementadas após 1964, o ensino de História torna-se alvo importante do poder político autoritário dominante e, nesse sentido, várias medidas governamentais são adotadas visando ao enquadramento ao binômio do regime: desenvolvimento econômico/segurança nacional" (Fonseca, 1995, p. 13).

Neste artigo buscamos discutir como os governos autoritários trataram a Educação, em especial a formação de professores naquele período, visando entender em que medida o Pibid contribuiu para superar esse modelo conservador, que persiste em rondar o ambiente educativo e as mentes de muitos educadores, sobretudo em relação à implantação do contato de graduandos dos cursos de Licenciatura com as escolas da Educação Básica desde o início do curso, experiência que, antes do Pibid, ocorria somente no final dos cursos de graduação.

O projeto político brasileiro, durante os governos ditatoriais, camuflava a redução da dimensão humanista e crítica no ensino com a difusão da ideia de que era preciso construir uma grande potência por meio de uma política educacional pautada na tecnocracia, o que provocou discussões e entraves entre o governo e os movimentos sociais de educadores durante a década de 1970. Esses debates foram responsáveis pela reformulação das propostas de ensino que, junto às lutas pela redemocratização política do país, foram responsáveis pelas reformas curriculares dos anos 1980 (Zamboni; Fonseca, 2008).

A Lei de Diretrizes e Bases n 4.024, sancionada em dezembro de 1961, já expressava claramente o ideário de segurança nacional e desenvolvimentista do país, visto que revela a dimensão privatista da Educação, representando os interesses dos grupos de empresários e dos representantes religiosos das Igrejas, fato importante a ser destacado, pois é a partir dele que analisaremos e compreenderemos as mudanças ocorridas no período, tais como: a reforma do ensino superior, propugnada pela Lei 5.540, de 28 de dezembro de 1968; a Lei 5.692, de 11 de agosto de 1971, que instituiu a reforma do $1^{\circ}$ e $2^{\circ}$ Graus, bem como implantou a disciplina de Estudos Sociais nos currículos escolares; e o Decreto-Lei 547, de 18 de abril de 1969, que estabelece os cursos superiores de licenciaturas de curta duração. Essas reformas foram responsáveis pela redução da já minúscula presença da perspectiva humanista no currículo escolar brasileiro, em benefício do tecnicismo e da fragmentação curricular, sentida 
sobremodo no eclipse das problematizações sobre o papel social dos cursos de formação de professores (Silva; Fonseca, 2010).

A reforma universitária foi implantada com a alegação de que pretendia promover o desenvolvimento e o progresso social, mas os críticos do governo expuseram que isso pretendia mascarar o seu verdadeiro ideal: o de modelar as instituições superiores de acordo com a ordem político-econômica imposta pelo regime militar. Com a Lei 5.540/68, as universidades viram o comprometimento de sua autonomia e da possibilidade de contestação e crítica no interior das instituições de ensino superior.

A reforma do ensino de $1^{\circ}$ e $2^{\circ}$ Graus, implantada durante o governo de Emílio Garrastazu Médici, enquadra-se no modelo ideal da reforma universitária. A Lei 5.692/1971 centrou atenção sobre o ensino de $2^{\circ} \mathrm{Grau}$, priorizando a formação de mão de obra para o trabalho, o que comprometeu a formação integral e humanística dos educandos e, como consequência, o pensamento crítico e reflexivo sobre si e sobre o mundo em que se encontravam inseridos. Isso repercutiu diretamente sobre o curso de História e sua estrutura curricular, pois segregou mais ainda a formação nuclear do curso e a docência, deixando o contato dos graduandos com o ensino apenas para o final do curso, nas disciplinas de Prática de Ensino ou de Estágio, no que ficou conhecido como o "fluxograma $3+1$ " (3 anos de formação nas áreas específicas do curso mais 1 ano de práticas de ensino, período no qual iniciava-se o contato com as escolas do Ensino Básico).

A reforma também trouxe consigo a descaracterização do ensino de História e Geografia, com a consolidação dos Estudos Sociais. Segundo o Conselho Federal de Educação, o ensino de Estudos Sociais deveria visar: "ao ajustamento crescente do educando ao meio cada vez mais amplo e complexo, em que deve não apenas viver, mas conviver, dando-se ênfase ao conhecimento do Brasil na perspectiva atual do seu desenvolvimento" (Fonseca, 2003, p. 41-42).

Os conteúdos de Estudos Sociais eram ministrados de maneira generalizante e retiraram as especificidades das áreas humanas (Geografia e História), que vivenciaram um momento de esvaziamento e diluição dos conteúdos, com o intuito de reforçar o caráter ufanista-nacionalista que pretendia justificar o projeto ideológico organizado pelos militares no país, a partir de 1964.

Para atender a demanda de profissionais da área de Estudos Sociais, o Decreto-Lei 547/69 permitiu a criação dos cursos de licenciaturas curtas, medida 
que atravessou o princípio de autonomia do professor e caracterizou-se pela intervenção do Estado em um processo de desqualificação do docente.

Além disso, os Estudos Sociais que, praticamente ignoravam as áreas de conhecimentos específicos em favor de saberes puramente escolares, contribuíram para um afastamento entre as universidades e as escolas de primeiro e segundo graus. Isso prejudicou o diálogo entre a pesquisa acadêmica e o saber escolar, bem como atrasou as necessárias introduções de reformulações do conhecimento histórico e das ciências pedagógicas no âmbito escolar. (Brasil, 1997, p. 18)

Selva Guimarães Fonseca aponta a institucionalização dos cursos de licenciaturas de curta duração como um "ataque à formação de professores". De acordo com a autora, objetivando atender às "carências de mercado", o Estado desconsiderou a formação longa e sólida em determinadas áreas profissionais, formando os professores polivalentes que ministravam, além de História e Geografia, Educação Moral e Cívica (EMC) e Organização Social e Política do Brasil (OSPB).

Percebe-se uma descaracterização do ensino das humanidades, sem falar que todas essas medidas resultaram na formação de profissionais que lecionavam os conteúdos como "um mosaico de conhecimentos gerais e superficiais da realidade social” (Fonseca, 2003, p. 20). O culto aos grandes nomes, aos feitos monumentais, ao amor à pátria e ao civismo foram marcas desse ensino. Portanto, o percurso feito pelo ensino de História até a década de 1970 se configurou, como já mencionado, tecnicista. A partir do início dos anos 1980, ocorreram mudanças objetivando contestar tal perspectiva de formação docente.

O retorno das disciplinas de Ciências Humanas (História e Geografia) ao currículo escolar de maneira autônoma, a partir das séries iniciais de escolarização, só começou a ser impulsionado durante os anos 1970, quando começou a ganhar força o movimento de diversos profissionais da Educação, desde a sala de aula até as universidades, que se uniram em organismos como a Associação Nacional dos Professores Universitários de História (Anpuh) e da Associação dos Geógrafos Brasileiros (AGB) para batalharem pela extinção das reformas que afetaram os cursos de formação docente e o currículo escolar, propondo a democratização do acesso ao ensino e a reestruturação do fluxograma dessas disciplinas. 
Com as lutas pela redemocratização política do país, houve também as conquistas no campo educacional, tendo sido propostas novas políticas públicas para a educação do país, com a intenção de superar os ideais que estagnaram o desenvolvimento crítico-reflexivo dos cidadãos brasileiros. Isso foi decisivo para a criação de ações efetivas na redemocratização do ensino de História, entre elas o Pibid, que serão discutidas a partir de agora.

\section{O Pibid HistóRia da UFPI: PERCURsos E CONTRIBUições}

O Pibid, no Brasil, foi instituído por uma parceria entre o Ministério da Educação (MEC), a Coordenação de Aperfeiçoamento de Pessoal de Nível Superior (Capes) e o Fundo Nacional de Desenvolvimento da Educação (FNDE). Implantado no dia 12 de dezembro de 2007, no governo de Luiz Inácio Lula da Silva, por meio da portaria normativa da Presidência da República $n^{\circ} 38$, buscou incentivar e valorizar o magistério, dando suporte aos estudantes de licenciatura das instituições federais de educação superior. Esse Programa tinha por objetivos:

I - incentivar a formação de professores para a educação básica, especialmente para o ensino médio; II - valorizar o magistério, incentivando os estudantes que optam pela carreira docente; III - promover a melhoria da qualidade da educação básica; IV - promover a articulação integrada da educação superior do sistema federal com a educação básica do sistema público, em proveito de uma sólida formação docente inicial; $\mathrm{V}$ - elevar a qualidade das ações acadêmicas voltadas à formação inicial de professores nos cursos de licenciaturas das instituições federais de educação superior. (Brasil, 2007 p. 2)

Esses objetivos vão ao encontro das novas políticas públicas que emergiram nos anos de redemocratização do país, preocupadas em propor medidas capazes de superar concepções, práticas e métodos excludentes, herdados de um passado recente, que engessaram saberes como se esses fossem conhecimentos prontos e acabados, podando o pensamento crítico e prejudicando a formação humanista (Fontineles; Sousa Neto, 2017).

No período de redemocratização do Brasil, principalmente a partir de 1988, novas políticas foram pensadas para a Educação, a fim de encaminhar o país a 
novos pressupostos educacionais. A educação passa a ser entendida como a porta de acesso a caminhos e oportunidades para os cidadãos brasileiros.

A elaboração de projetos teóricos organizados pelo Estado no período da redemocratização do Brasil - a Constituição Federal de 1988, a nova Lei de Diretrizes e Bases da Educação (LDB - Lei 9.394), em 1996, e os Parâmetros Curriculares Nacionais (PCNs), em 1997 - salientava a importância da escola, da formação de professores e de um ensino mais dinâmico e inovador, que relacionasse o conteúdo visto em sala de aula com a realidade vivenciada pelos estudantes.

Essas políticas visavam o desenvolvimento de um ensino inclusivo, objetivando uma formação crítico-reflexiva, procurando se distanciar da política adotada nos governos militares que encaixotava saberes como se esses fossem conhecimentos apartados da sociedade, o que podava o pensamento crítico e prejudicava a formação humana.

Conforme o regimento do Pibid UFPI (Brasil, 2008), o Programa foi instituído na Universidade no ano de 2008, de acordo com a resolução Cepex 208/08, de 11 de novembro do mesmo ano, e ratificado pela Resolução Cepex 223, de 12 de dezembro de 2008. O documento informa que o projeto Pibid UFPI estava em sintonia com os objetivos propostos em sua missão: formar docentes críticos, reflexivos e conscientes no contexto profissional, por meio da valorização da formação dos estudantes dos cursos de licenciaturas, promovendo o contato dos licenciandos com a realidade escolar, encaminhando-os ao desenvolvimento e aprimoramento de competências inerentes ao ensino, à pesquisa e à extensão.

Somente no ano de 2009 o Programa foi efetivamente implantado, com 54 alunos bolsistas de oito áreas da licenciatura, ou subprojetos distintos (Biologia, Física, Geografia, Pedagogia, Letras, Matemática, Artes e Química), que passaram a desenvolver atividades que, a princípio, estavam restritas a uma única escola da rede estadual da cidade de Teresina (ver Eduardo, 2012; Frota, 2017).

No ano de 2010, a UFPI propôs dois editais que possibilitaram a expansão do Pibid. Isso decorreu de dois fatores primordiais: 1. novas áreas contempladas: o campus Ministro Petrônio Portella, em Teresina, passou a oferecer bolsas para a Ciência da Natureza, História (foco da nossa pesquisa), Sociologia e Educação Física, e nos campi do interior do estado passou a contemplar "Pedagogia, Biologia, Matemática e a Licenciatura em Educação no Campo" 
(Andrade, 2014, p. 46); e, 2. maior número de bolsas disponibilizadas aos estudantes - só em Teresina, o Pibid passaria a contar com 258 bolsistas.

Em 2011, segundo o relatório da Diretoria de Educação Básica Presencial (DEB), o Pibid já era o segundo maior programa de bolsas da Capes, com tendência para o crescimento. No período de 2009 a 2011, o desenvolvimento do Pibid, se comparado ao Pibic (Programa Institucional de Bolsas de Iniciação Científica), alcançou números que, no Pibic, só foram atingidos após 20 anos.

No ano de 2012, por meio do décimo primeiro edital Capes/Pibid, o Programa almejava alcançar 45 mil bolsas em todo o país. Contudo, houve uma superação dessa meta, atingindo um total de 49.321 bolsas, o que evidenciou a consistência e a expansão do projeto.

Em 2013, segundo a DEB 2009/2013, o número de bolsas cresceu consideravelmente, conforme apresentado na Figura 1.

Figura 1 - Evolução do período de bolsas concedidas e implementadas no período 2009-2013

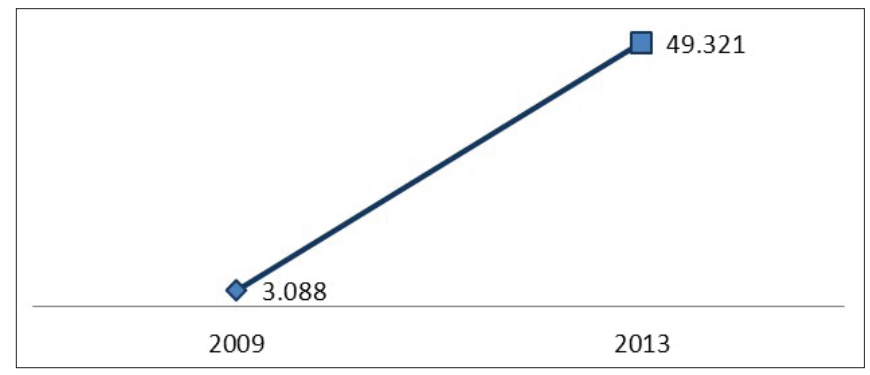

Fonte: Diretoria de Educação Básica - DEB: Relatório Pibid 2009-2013.

Segundo a DEB/Capes 2009-2013, o Nordeste aparecia como a região que concentrava a maior quantidade de bolsas de todo o país. Isso representava um grande incremento financeiro na região, mas, principalmente, o forte investimento na formação docente na região, o que indica o interesse governamental em qualificar o magistério no Nordeste: 
Tabela 1 - Quantidade de bolsas Pibid no Brasil (2009-2013)

\begin{tabular}{l|c|c|c}
\hline \multicolumn{1}{c|}{ Região } & $\begin{array}{c}\text { Bolsistas de Iniciação } \\
\text { à Docência }\end{array}$ & $\begin{array}{c}\text { Coordenadores } \\
\text { e supervisores }\end{array}$ & Total \\
\hline Norte & 4.408 & 1.000 & 5.408 \\
Nordeste & 11.789 & 2.489 & 14.278 \\
Centro-Oeste & 3.565 & 906 & 4.471 \\
Sudeste & 10.931 & 2.569 & 13.500 \\
Sul & 9.399 & 2.265 & 11.664 \\
\hline Total & 40.092 & 9.229 & 49.321 \\
\hline
\end{tabular}

Fonte: DEB/Capes 2009-2013.

Dessas 14.278 bolsas, 2.077 eram oferecidas no estado do Piauí que, nesse período, contava com a participação de três IES, com 226 campi e 84 subprojetos. Dessa forma, a UFPI,

com o Edital Pibid no 61/2013, passou a configurar como a universidade com a maior quantidade de bolsas disponibilizadas, distribuídas por todas as licenciaturas da instituição. Totalizando 1.820 (um mil, oitocentas e vinte) bolsas, sendo 1.560 (um mil, quinhentas e sessenta) destinadas aos alunos-bolsistas, 177 (cento e setenta e sete) aos supervisores de área (professores das escolas municipais e estaduais conveniadas), 78 (setenta e oito) aos coordenadores de área (professores da UFPI), 4 (quatro) aos coordenadores de área de gestão de processos educacionais e 1 (uma), à coordenação institucional do programa. (Andrade, 2014, p. 46)

Nos 3 anos que se seguiram, entretanto, o Pibid/Capes, de maneira geral, e o Programa da UFPI, de maneira específica, começaram a apresentar uma redução no número de bolsas, com dados inferiores àqueles referentes aos seus anos iniciais, uma vez que, no período, o país passou por cortes na previsão orçamentária voltada para a Educação.

Conforme a análise feita sobre os editais do programa na IES em questão, em 2014 o Pibid da UFPI apresentou em seu edital de janeiro 1.580 bolsas disponibilizadas para aquele ano na IES. Somente para o campus Ministro Petrônio Portella, em Teresina (PI), foram ofertadas 770 bolsas, das quais 40 estavam destinadas ao curso de História. No dia 7 de outubro do mesmo ano, quando foi 
reaberto o edital, foram disponibilizadas mais 88 bolsas para o campus da IES de Teresina, porém, a área de História não chegou a ser contemplada.

Já em 2015, somando os dois editais - o aprovado no dia 26 de março e o do dia 23 de outubro -, em edital complementar foram disponibilizadas 255 bolsas para os diversos cursos da UFPI. No campus de Teresina, foram ofertadas 133 bolsas, das quais somente 7 foram destinadas para estudantes da graduação de licenciatura em História.

Em 2016, o edital Pibid/Capes/UFPI, divulgado e aprovado em 20 de julho, confirmou 108 bolsas, 30 para o campus de Teresina, mas dessas, apenas 2 foram para a área de História. Já no edital de 24 de novembro de 2016 foram ofertadas para a UFPI, campus Ministro Petrônio Portella, 19 bolsas, havendo, novamente, apenas 2 vagas para o curso de História. Findou-se, assim, o ano de 2016 com 4 bolsas para a área de História. O Programa começava a sofrer cortes expressivos, o que traduz a configuração político-econômica que atravessava o país no período.

Em Teresina, a ameaça e os cortes no Programa ficaram mais evidentes em 2016, mobilizando professores, coordenadores, professores supervisores e bolsistas do Pibid da UFPI, da Universidade Estadual do Piauí (Uespi) e do Instituto Federal de Educação, Ciência e Tecnologia do Piauí (IFPI). Em protestos realizados no mês de fevereiro, na praça Pedro II, região central da capital piauiense, os manifestantes reivindicaram a manutenção do Pibid, bem como fizeram questão de evidenciar a sua contribuição para a vida acadêmica dos bolsistas e para a qualidade da educação do país.

Figura 2 - Estudantes pedem a manutenção do Pibid em Teresina, PI

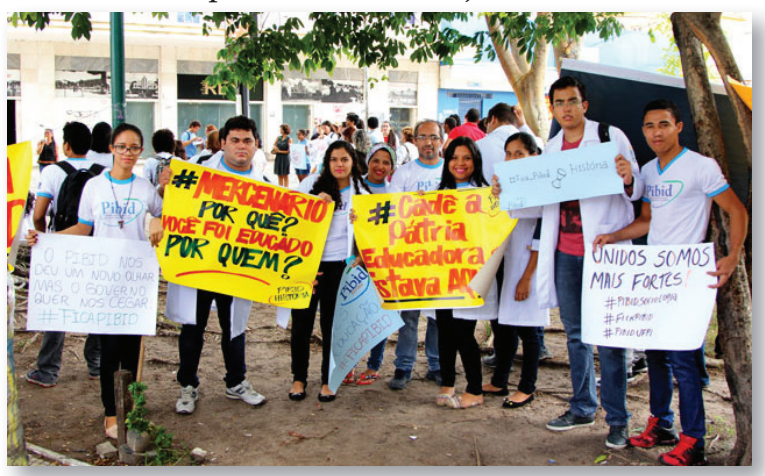

Foto: Gabriel Torres/CT. Fonte: http://www.capitalteresina. com.br/noticias/educacao/tres-mil-estudantes-no-piauiserao-prejudicados-com-cortes-no-pibid-38447.html. 
O Pibid, tanto em nível nacional como na UFPI, considerando desde seu primeiro edital, foi pensado e constituído buscando contribuir para a formação dos professores, em especial os de História.

Entre os sujeitos que participam de maneira direta no Pibid, vale destacar: o bolsista (graduando em licenciatura), o supervisor de área (professor formado que atua na Educação Básica), o coordenador de área (professor da universidade que orienta os bolsistas), a coordenação de gestão (professor universitário que apoia a coordenação institucional) e a coordenação institucional (professor universitário que, entre outras funções, responde pela coordenação geral do Pibid perante as instâncias superiores à IES, da Secretaria de Educação e a Capes).

Essa disposição do Programa favorece o que seria uma das maiores conquistas do Pibid: o envolvimento dos diferentes sujeitos do processo educativo no contexto de formação inicial dos graduandos de História: o próprio graduando, professores universitários de seu curso, professores da Educação Básica, além dos estudantes e da comunidade escolar das escolas públicas. Isso favorece o convívio e a qualificação desses graduandos desde o início de sua formação inicial. $\mathrm{O}$ andamento do Programa facilita a dinâmica de formação de professores e a melhoria da qualidade dos componentes curriculares ou subprojetos da área beneficiada pelo Pibid (Fontineles; Sousa Neto, 2017). Além disso,

Os projetos devem incentivar e promover a vivência dos estudantes no cotidiano das escolas públicas durante a sua formação acadêmica, para que desenvolvam atividades didático-pedagógicas sob a orientação de um docente do curso de licenciatura e de um professor da escola com formação na área de atuação do licenciando. Dessa forma, os licenciandos terão como (co)formadores os professores supervisores que atuam na rede, como os responsáveis pela sua introdução no cotidiano escolar, designados para supervisionar as atividades dos bolsistas de iniciação à docência. Eles acompanham as atividades presenciais dos licenciandos, ao mesmo tempo em que orientam os projetos a serem desenvolvidos nas escolas, participam de seminários, reuniões, atividades de formação, avaliação e reflexão pertinentes ao programa. Esses profissionais, ao se envolverem com o Programa, se inserem num movimento de formação continuada por meio de cursos e em desenvolvimento de projetos na escola, junto com os licenciandos. Por outro lado, os coordenadores de área - professores universitários - passam a 
participar também da rotina da Educação Básica, qualificando as atividades curriculares desenvolvidas na universidade. (Neitzel, 2013, p. 5)

A concessão de bolsas ${ }^{2}$ se apresenta como um estímulo a todos os sujeitos envolvidos no Pibid e contribui para a eficiência e a eficácia do Programa, pois reforça a valorização da docência. ${ }^{3}$ Entretanto, a quantia em si não representa o principal motivo da permanência e atuação de cada sujeito no projeto, pelo menos não para os sujeitos entrevistados nesta pesquisa, visto que as atribuições e a cooperação entre os integrantes do Programa voltam-se, sobretudo, para o aperfeiçoamento docente e a melhoria da qualidade do ensino em cada área do saber beneficiada.

Nesse sentido, há pesquisadores que salientam a abrangência dessa iniciativa para ir além da dimensão pecuniária: Talvez a proposição de remuneração tenha sido o primeiro impacto causado por este Programa na comunidade acadêmica para atrair seu interesse, mas os ganhos advindos de sua implantação são muito mais abrangentes e fecundos. (Fontineles; Sousa Neto, 2017, p. 12)

Participar do Pibid representa a oportunidade de se aperfeiçoar profissionalmente e contribuir para melhoria da Educação no país. Nas palavras do ex-coordenador de área do Pibid-História na UFPI, Denílson Botelho de Deus, ${ }^{4}$

O exercício da coordenação neste Programa foi, em primeiro lugar, muito prazeroso e gratificante para mim. Voltar a frequentar cotidianamente as salas de aula do ensino básico, enfrentando junto com os bolsistas do Pibid os desafios do dia a dia no ensino médio foi estimulante. Além disso, foi mais uma oportunidade de reiterar a certeza de que ninguém se faz professor de um dia para o outro, assim que se forma. A gente se faz professor atuando de forma persistente e engajada no dia a dia, na sala de aula, ano após ano. Compartilhar esse aprendizado com os alunos da licenciatura é estimulante. (Deus, 2014, p. 1)

Entretanto, alguns bolsistas não desconsideram o valor da ajuda que a bolsa proporciona, relatando até mesmo a sua importância para o custeio de despesas com os estudos e/ou despesas de ordem pessoal e para a sua manutenção na graduação, como a ex-bolsista Mariana Mendes Oliveira: ${ }^{5}$ 
Quero falar da importância da bolsa do Pibid, no sentido da minha permanência para a conclusão do meu curso. A bolsa tem sido fundamental no sentido de proporcionar o meu deslocamento, a questão do transporte urbano, porque moro distante e preciso pegar ônibus para a universidade e também tem a questão do material didático: livros e xerox. Se não fosse ela, não sei se ainda estaria estudando, até porque eu não trabalho. (Oliveira, 2015)

Corroborando o que declarou Mariana, outra ex-bolsista, Viviam Cathaline de Sousa Ferreira, ${ }^{6}$ declara que a bolsa representava a soma do aprendizado e da "independência" financeira, uma vez que esse auxílio financeiro contribuiu para que ela deixasse de ser um "peso" para a família e se tornasse uma pessoa produtiva na sua área de estudo:

Outra grande importância do Pibid para mim é a questão financeira, porque quando a gente entra na universidade, vinda de família humilde, a gente vem mesmo com a cara e com a coragem e, a partir do momento que eu tinha o valor, que não é um valor absurdo, mas que me ajuda a me manter na universidade, eu já não preciso ser um peso para minha família, pelo contrário, eu sou uma pessoa produtiva, não que lucra, não vou trazer benefícios para família, que vai ajudar na economia do lar, não é esse o fundamento do Pibid, mas eu vou ser uma estudante que é produtiva para a academia - porque estou recebendo para aquilo, eu não preciso pensar em me deslocar para outro serviço, estou totalmente dedicada àquilo - eu sou também, ao mesmo tempo, uma estudante produtiva para a sociedade, porque eu entro e dou retorno ao voltar à sala de aula, na medida do possível, mas eu dou um retorno e sou produtiva para a minha família, porque eu deixo de ser um peso, eu passo a ser uma vitória, vamos pensar assim. (Ferreira, 2016, p. 2)

Com os relatos dos ex-bolsistas, percebemos que a bolsa é salientada como um dos aspectos mais positivos do Pibid, além de promover a articulação entre teoria e prática, entre a Educação Básica e o Ensino Superior, entre os professores formadores e os graduandos em formação. Mas quais princípios pedagógicos norteiam o Pibid? Segundo Ana Paula Soares de Andrade, ao referenciar as pesquisas da diretora de Formação de Professores da Educação Básica da Capes, Carmen Moreira de Castro Neves, os princípios pedagógicos do Pibid foram 
embasados a partir dos estudos de Antonio Nóvoa (1992), que refletiu sobre a formação de professores construída dentro da profissão. São eles:

1. Formação de professores referenciada no trabalho, na escola e na vivência de casos concretos, enriquecidos com reflexão e construção de conhecimento em níveis crescentes de complexidade; 2 . formação de professores realizada com a combinação do conhecimento teórico e metodológico dos professores das instituições de ensino superior e o conhecimento prático e vivencial dos professores das escolas públicas; 3 . formação de professores atenta às múltiplas facetas do cotidiano da escola e à investigação e à pesquisa que levam à resolução de situações e à inovação na educação; 4 . formação de professores realizada com diálogo e trabalho coletivo, realçando a responsabilidade social da profissão. (Andrade, 2014, p. 44)

Esses princípios permitem (re)pensar e (re)significar o contexto escolar, abrindo a possibilidade de adotar práticas inovadoras sob um viés integrador e horizontal entre educadores e educandos, e mesmo entre colegas de profissão. Conhecer a realidade escolar e trabalhar em equipe, trocando aprendizados, faz parte desse processo formativo de professores. Por isso, a proposta pedagógica de Antonio Nóvoa representa tão bem os objetivos que norteiam o Pibid.

Conforme os editais publicados pela UFPI, o Pibid objetiva valorizar e orientar o magistério, assim como se articula a partir do paradigma reflexivo, que busca formar profissionais pela experiência e pelo contato destes com a sala de aula. Dessa forma, há a necessidade de organizar e controlar as atividades realizadas pelos discentes/pesquisadores integrantes do programa, e isso se dá, sobretudo, pelo procedimento metodológico adotado, o qual compreende três eixos de ações fundamentadas pelo princípio central, que é "saber fazer, aprender fazendo".

Para Andrade (2014), o Pibid atua sobre três eixos, que correspondem aos meios pelos quais os bolsistas desenvolvem, em conjunto com as escolas públicas conveniadas ao Programa, suas atividades no cotidiano escolar no projeto Pibid-UFPI.

Os três eixos de ações metodológicas - o das ações de monitoria, o das ações prático-pedagógicas e o das ações complementares - compreendem, respectivamente: as atividades feitas pelos bolsistas com grupos de alunos da escola conveniada, que precisam de acompanhamento e reforço do conteúdo 
ministrado em sala de aula; os planejamentos realizados pelos discentes/bolsistas, em conjunto com seus coordenadores de área a cada início de período letivo, quando se pensa, discute e se produzem as atividades que serão aplicadas no decorrer do ano; e, por fim, as atividades ofertadas pelos bolsistas de cunho complementar à formação escolar, em que elas são ofertadas em forma de oficinas, minicursos, exibição de filmes e palestras, entre outros.

Os eixos norteadores do Programa contribuem, assim, para formação dos bolsistas envolvidos, ao passo que favorecem a aproximação entre Academia e Educação Básica:

Os três eixos destacados neste Projeto deixam notória a dimensão voltada para a formação docente entre os graduandos e seu contato com a Educação Básica, através daquilo que Monteiro [...] denomina de "mediação didática", por meio da qual o acadêmico-bolsista deveria perceber sua ação como "intermediária”, no sentido de mediar os saberes que o estudante já tem e os que são viabilizados no cotidiano escolar pela ação docente possibilitada pelos acadêmicos - articulando a exposição teórica, que seria o estado do conhecimento - e a exposição didática, que seria o estado de quem conhece, na promoção de ações que estimulem a aprendizagem nos estudantes envolvidos. (Fontineles; Sousa Neto, 2017, p. 13)

A mediação didática busca, por uma relação horizontal na construção do saber escolar, revelar a originalidade do saber acadêmico no ofício do professor, permitindo que os estudantes consigam dar significado a esse conhecimento e empregá-lo em seu cotidiano, sendo por isso uma construção social, que nasce no seio da comunidade escolar. "Uma realidade construída por mediações contraditórias, relações complexas, não imediatas, com um profundo senso de dialogia" (Monteiro, 2016, p. 18).

Para a coordenadora de área, Vilmar Aires dos Santos, ${ }^{7}$ que ingressou no Pibid em 2011, por ser ela docente da Prática de Ensino/Estágio no curso de História da UFPI, o Programa proporciona inúmeros aprendizados. Entre estes, a professora ressalta um com o qual se identifica: "o sentimento de estar contribuindo para a formação docente de forma mais consistente e atrativa para dezenas de jovens que escolheram a docência como opção profissional" (Santos, 2016, p. 2).

Como coordenadora de área, a professora se coloca antes de tudo em seu papel de educadora e formadora de professores. Por estar em uma das funções 
que sustentam o Pibid, ela acredita que suas experiências e vivências podem revelar uma nova maneira de se ver a docência, a licenciatura e o ensino de História. Por isso, afirma ainda:

Vejo o Pibid como um Programa (o único que conheci com ênfase na formação docente), como uma luz no fim do túnel na formação de professores, pois, nos últimos anos, as licenciaturas têm perdido alunos que preferem escolher outros cursos ou o fazem apenas para ter uma formação superior, com o objetivo de buscar aprovação em algum concurso. A docência não tem mostrado atrativos para os jovens, que terminam por escolhê-la como última opção. Tenho consciência que o Pibid não é a receita para isso, mas vejo o Programa como uma primeira ação na tentativa de atrair bons alunos para os cursos de professores, uma vez que dá ao bolsista a oportunidade de um aprendizado do ofício docente ao longo do curso, promove uma aproximação entre a academia e a escola de educação básica, resgata o docente em exercício como colaborador na formação de novos professores (os supervisores) e proporciona um importante apoio financeiro aos alunos bolsistas, o que pode significar a possibilidade do não abandono do curso por dificuldades financeiras. Por tudo isso e por outras coisas, defendo o Programa como uma ação importante no sentido de trilhar caminhos que levem à formação e atuação docente com mais qualidade e entusiasmo. (Santos, 2016, p. 1)

A principal importância do Pibid, segundo a ex-coordenadora do Pibid/ História, é justamente a formação de professores, tanto no âmbito inicial como na sua continuidade. Por meio do Programa, a professora acredita ser possível um (re)despertar da docência e das licenciaturas, com mais qualidade e entusiasmo. Essa política pública oferece suportes para isso. Apesar de não aparecer como solução para todos os problemas da formação de professores e da educação do país, já se configura - como a professora pontua - "como uma luz no fim do túnel" (Santos, 2016, p. 1).

\section{CONSIDERAÇÕES FINAIS}

Entre os inúmeros objetivos traçados pelo Pibid, é fundamental destacar o que contribui significativamente para a formação docente dos seus bolsistas: a oportunidade de um contato com a sala de aula da Educação Básica por meio das escolas beneficiadas. Esse contato e esse convívio proporcionam aos 
pibidianos a possibilidade de criação e participação em experiências metodológicas, tecnológicas e práticas docentes, que contribuem para seu envolvimento e amadurecimento em relação à docência e ao compromisso profissional e social desse ofício.

O Programa possibilita, ainda, o ensino e a aprendizagem dos saberes específicos para ensinar o componente curricular de cada área nas escolas em que os bolsistas atuam, por meio dos eixos norteadores que regem as suas atividades, assim como a estrutura de funcionamento do Pibid permite a articulação dos sujeitos envolvidos no projeto. Além disso, contribuiu para todos os envolvidos atuarem diretamente no processo de intervenção do ensino de História, uma vez que torna possível romper com uma estrutura rígida, advinda do modelo de ensino autoritário, herdado do período ditatorial, que ainda permanece em parte das instituições de ensino. O Pibid busca romper com essa tradição de ensino brasileiro pela adoção de métodos que incentivam a aproximação de todos os bolsistas com a comunidade escolar da Educação Básica, possibilitando aos envolvidos reconhecerem-se como sujeitos históricos.

Assim sendo, o Programa se consolida na pesquisa como de extrema relevância não só para os graduandos do curso de História da UFPI, mas também para os estudantes das escolas públicas atendidas. Isso se constata porque o Pibid estimula a vontade de estudar, de pesquisar, de aprender, de sociabilizar, enfim, de ser um cidadão crítico-reflexivo dentro da sociedade em que estamos inseridos, propondo uma educação que supere os resquícios de um passado recente autoritário, que tanto dano causou à Educação brasileira, em especial ao ensino de História. Passado esse que insiste em nos assombrar, mas que precisa ser conhecido, discutido e combatido pela consciência histórica.

\section{REFERÊNCIAS}

ANDRADE, Ana Paula S. de. O impacto do Pibid Educação Física na trajetória dos alunos bolsistas e na prática pedagógica de professores supervisores. 2014. Dissertação (Mestrado) - Universidade Federal do Triângulo Mineiro (UFTM). Uberaba, 2014. Disponível em: bdtd.uftm.edu.br. Acesso em: 1 out. 2015.

ALBERTI, Verena. Manual de história oral. 3. ed. Rio de Janeiro: Ed. FGV, 2005.

ALBERTI, Verena. Ouvir para contar: textos em história oral. Rio de Janeiro: Ed. FGV, 2004. 
BRASIL. Diretoria de Educação Básica - DEB. Relatório do Pibid 2009/2011. Disponível em: https://www.capes.gov.br/images/stories/.../DEB_Pibid_ Relatorio-2009_2011.pdf. Acesso em: 5 dez. 2016.

BRASIL. Diretoria de Educação Básica - DEB. Relatório do Pibid 2009/2013. Disponível em: https://www.capes.gov.br/images/stories/.../2562014-relatrorio-DEB-2013-web.pdf. Acesso em: 5 dez. 2016.

BRASIL. Ministério da Educação e da Cultura (MEC), Teresina, PI, 2008. Regimento interno do Pibid UFPI. Disponível em: leg.ufpi.br/subsiteFiles/pibid/arquivos/files/ regimento_inter... Acesso em: 5 nov. 2016.

BRASIL. Secretaria de Educação Fundamental. Parâmetros Curriculares Nacionais: história e geografia. Brasília/MEC/SEF, 1997. Disponível em: portal.mec.gov.br/ seb/arquivos/pdf/livro051.pdf. Acesso em: 31 ago. 2015.

BRASIL. Lei de Diretrizes e Bases da Educação. Lei n. 4.024, 20 dez. 1961. Disponível em: http://www2.camara.leg.br/legin/fed/lei/1960-1969/lei-4024-20-dezembro-1961-353722-publicacaooriginal-1-pl.html. Acesso em: 31 jan. 2019.

BRASIL. Lei de reforma universitária. Lei n. 5.540, 28 nov. 1968. Disponível em: http:// www2.camara.leg.br/legin/fed/lei/1960-1969/lei-5540-28-novembro-1968-359201-publicacaooriginal-1-pl.html. Acesso em: 31 jan. 2019.

BRASIL. Decreto Lei que estabelece os cursos de licenciaturas de curta duração. Decreto Lei no 547, 18 abr. 1969. Disponível em: http://www2.camara.leg.br/legin/fed/declei/1960-1969/decreto-lei-547-18-abril-1969-374120-publicacaooriginal-1-pe. html. Acesso em: 31 jan. 2019.

BRASIL. Lei de reforma do ensino de $1^{\circ}$ e $2^{\circ}$ grau. Lei 5.692, 11 ago. 1971. Disponível em: http://www2.camara.leg.br/legin/fed/lei/1970-1979/lei-5692-11-agosto-1971-357752-publicacaooriginal-1-pl.html. Acesso em: 31 jan. 2019.

BRASIL. Portaria Normativa n. 38, 12 dez. 2007. Disponível em: https://www.capes. gov.br/images/stories/download/legislacao/Portaria_Normativa_38_PIBID.pdf. Acesso em: 31 jan. 2019.

DEUS, Denílson B. de. Entrevista com ex-coordenador do Pibid-História Capes/UFPI. [mensagem pessoal. e-mail] mensagem recebida por Thiago Rodrigues Frota em 7 out. 2014.

EDUARDO, Emanoel Junio. O papel do Pibid na ótica dos licenciandos-bolsistas: um estudo de caso. 2012. Monografia (Licenciatura em Química) - Universidade de Brasília (UnB). Brasília, 2012. Disponível em: http://bdm.unb.br/bitstream/10483/4084/7/2012_EmanoelJunioEduardo.pdf. Acesso em: 13 out. 2015.

FERREIRA, Viviam C. de Sousa. Entrevista com ex-bolsista do Pibid-História Capes/ UFPI. Entrevista concedida na UFPI, Campus Ministro Petrônio Portella em 4 nov. 2016 a Thiago Rodrigues Frota e Claudia Cristina da Silva Fontineles. (Mimeogr.). 
FREIRE, Paulo. Pedagogia da autonomia: cartas pedagógicas e outros escritos. São Paulo: Ed. Unesp, 2000.

FROTA, Thiago Rodrigues. O Pibid-História e sua contribuição para a qualidade do ensino e formação docente na UFPI. 2017. Monografia (Licenciatura em História) - Universidade Federal do Piauí (UFPI). Teresina, 2017.

FONSECA, Selva G. Didática e prática de ensino de História: experiências, reflexões e aprendizagens. 11. ed. Campinas: Papirus, 2003.

FONSECA, Selva G. O uso de diferentes linguagens no ensino de história e geografia. Ensino em Re-Vista, São Paulo, v. 4, n. 1, 1995.

FONTINELES, Cláudia Cristina da S.; SOUSA NETO, Marcelo de. Transformações na oficina de História: o Pibid e a "variação de enredo" na formação de professores. Revista Unisinos, v. 21, n. 2, 2017. Disponível em: http://revistas.unisinos.br/index. php/historia/article/view/htu.2017.212.05. Acesso em: 18 jan. 2019.

GUIMARÃES, Valter S. Formação de professores: saberes, identidades e profissão. Campinas: Papirus, 2004.

MONTEIRO, Ana Maria. Ensino de História: entre história e memória. Disponível em: www.ufrrj.br/graduacao/prodocencia/publicacoes/pesquisa-pratica.../artigo1.pdf. Acesso em: 5 jun. 2016.

NEITZEL, Aldair de Aguiar. O impacto do Pibid nas licenciaturas e na Educação Básica. Conjectura: Filos. Educ., Caxias do Sul, v. 18, n. especial, p. 98-121, 2013. Disponível em: www.ucs.br/etc/revistas/index.php/conjectura/article/download/2062/1436. Acesso em: 29 out. 2016.

NÓVOA, António (org.). Vidas de professores. 2. ed. Porto: Porto Ed., 1992.

OLIVEIRA, Mariana M. Pibid História-UFPI. Teresina, YouTube, 6 out. 2015. Mídia criada em defesa do Pibid-História da UFPI. Disponível em: https://www.youtube. com/watch?v=iCL3o_zfMhk. Acesso em: 15 out. 2015.

PINSKY, Jaime; PINSKY, Carla B. O que e como ensinar: por uma história prazerosa e consequente. In: KARNAL, Leandro (org.). História na sala de aula: conceitos, práticas e propostas. 5. ed. São Paulo: Contexto, 2008.

REIS, Carlos Eduardo dos. A formação do professor de História. Perspectiva, Florianópolis, v. 17, n. Especial, p. 49-63, jan./jun. 1999. Disponível em: https:// periodicos.ufsc.br/index.php/perspectiva/article/download/11207/10674. Acesso em: 3 jun. 2016.

RÜSEN, Jörn. Razão histórica: fundamentos da ciência histórica. Brasília: Ed. UnB, 2001.

SANTOS, Vilmar Aires dos. Entrevista concedida em 13 jan. 2015 aos bolsistas do Pibid-História UFPI, Campus Ministro Petrônio Portella, Teresina, Piauí, sob orientação da professora doutora Cláudia Cristina da Silva Fontineles. (Mimeogr.). 
SILVA, Marcos Antônio da; FONSECA, Selva G. Ensino de História hoje: errâncias, conquistas e perdas. Revista Brasileira de História, São Paulo: Anpuh, v. 30, n. 60, p. 13-33, 2010.

ZAMBONI, Ernesta; FONSECA, Selva G. (org.). Espaços de formação do professor de História. Campinas: Papirus, 2008.

\section{NOTAS}

${ }^{1}$ Entendida por Rüsen (2001) como "a soma das operações mentais com as quais os homens interpretam sua experiência da evolução temporal de seu mundo e de si mesmos, de forma tal que possam orientar, intencionalmente, sua vida prática no tempo".

${ }^{2} \mathrm{O}$ estudante bolsista recebe $\mathrm{R} \$ 400,00$ para desempenhar suas atividades; o supervisor de área, $R \$ 765,00$; os coordenadores de área e de gestão, $R \$ 1.400,00$, e a coordenação institucional, $\mathrm{R} \$ 1.500,00$.

${ }^{3}$ Saberes compartilhados, um conjunto de significados e comportamentos em relação ao campo profissional.

${ }^{4}$ Tem Graduação, Mestrado e Doutorado em História. Foi professor efetivo do curso de Licenciatura em História da Universidade Federal do Piauí e do Programa de PósGraduação em História da Universidade Federal do Piauí (UFPI) e coordenador do Pibid/ História/UFPI. Atualmente é professor da Universidade Federal de São Paulo (Unifesp).

${ }^{5}$ Tem Graduação em História pela Universidade Federal do Piauí (UFPI) e experiência na área de História, com ênfase em História do Brasil. Integrou o Pibid-História UFPI 2012-2016.

${ }^{6}$ Mestranda do Programa de Pós-Graduação em História do Brasil (UFPI). Graduada em Licenciatura em História pela Universidade Federal do Piauí (UFPI). Atuou como bolsista do Programa Institucional de Bolsa de Iniciação a Docência (Pibid) entre 2013 e 2014, e como bolsista do Programa Institucional de Incentivo à Pesquisa (Pibic) entre 2014 e 2015. Atualmente é professora titular de História do Ensino Fundamental em escola particular da cidade de Teresina.

${ }^{7}$ Graduada em Licenciatura em História pela Universidade Federal do Piauí (UFPI), Mestre em Educação pela Universidade Federal do Ceará (UFC); Atualmente Professora Adjunta II - DMTE/CCE/UFPI, ministrando disciplinas para os cursos de Licenciatura em Pedagogia e Licenciatura em História. Atuou como Coordenadora do Pibid/UFPI, Campus Petrônio Portella, entre 2011 e 2017.

Artigo recebido em $1^{\circ}$ de junho de 2019. Aprovado em 13 de dezembro de 2019. 